Installation Technology Transfer Program

\title{
Development of the Army Facility Mission Dependency Index for Infrastructure Asset Management
}

Michael N. Grussing, Steve Gunderson, Mary Canfield,

September 2010

Ed Falconer, Albert Antelman, and Samuel L. Hunter 



\section{Development of the Army Facility Mission Dependency Index for Infrastructure Asset Management}

Michael N. Grussing and Samuel L. Hunter

Construction Engineering Research Laboratory

U.S. Army Engineer Research and Development Center

2902 Newmark Drive

Champaign, IL 61822

Steve Gunderson, Mary Canfield, Ed Falconer, and Albert Antelman

Naval Facilities Engineering Command

Engineering Service Center

1100 23rd Street

Port Hueneme, CA 93043

Final report

Approved for public release; distribution is unlimited.

Prepared for U.S. Army Corps of Engineers

Washington, DC 20314-1000

Under Project FY09-39, “MDI Methodology” 


\begin{abstract}
This report describes a Mission Dependency Index (MDI) developed for U.S. Army facility asset management. The MDI is an indicator of mission-related importance of Army infrastructure elements to be used for the purpose of providing more effective local prioritization of facilities for sustainment, restoration, and modernization (SRM) actions. It does this by evaluating the mission impact of interrupting a function or relocating where it is provided. The index is reported on a scale of $0-100$, and is analogous in that respect with existing Corps of Engineers Sustainment Management System (SMS) indices. As part of this work, an MDI methodology directly fit to Army-specific missions, facility resource capabilities, and organizational structure was developed. This was accomplished through a pilot implementation at White Sands Missile Range. The objectives of the demonstration were to identify Army-specific MDI criteria, develop a standardized implementation process, determine the steps for integrating MDI information into garrison-level and Army-level facility management business processes, and identify considerations and requirements for incorporating Army MDI criteria into the BUILDER ${ }^{\circledR}$ SMS. The results of an MDI analysis, as facilitated using the implementation and integration procedures recommended here, will enable facility decision makers to focus on infrastructure most critical to mission effectiveness.
\end{abstract}




\section{Executive Summary}

The U.S. Navy and U.S. Coast Guard codeveloped an operational risk metric called the Mission Dependency Index (MDI), which describes the relative importance of an infrastructure asset (facility) in terms of its mission criticality. The MDI process documents and measures intradependencies within a mission and interdependencies between missions. This process was deployed across the Navy, Coast Guard, Air Force, and the National Aeronautics and Space Administration (NASA). This project evaluated the specific requirements to tailor the MDI process to U.S. Army missions, tasks, and facility/ resource capabilities. It also developed guidance for effectively implementing MDI for Army installations.

The information needed to calculate the MDI metric is generated from interviews with operations and facility decision makers. The first step in the MDI process is to succinctly categorize the list of missions performed at each installation and identify the points of contact (POC) for each mission. Intradependencies are then created by linking the specific buildings and other support structures at the installation to each mission. For each facility, the interview process then determines facility interruptability, which measures how long functions supported by the facility could be stopped without adverse impact on the mission. The interview process also determines relocatability, which measures whether the mission could be relocated to other fixed or temporary facilities. These questions have been tailored to reflect the way the Army uses its facilities and responds to contingencies.

After several missions have been established and facilities have been evaluated using this process, mission interdependencies are then assessed. Interdependencies measure the indirect effect of other facilities not controlled by the unit. In other words, it evaluates the dependency of one mission's output on the execution of a different mission.

The result of this process is an MDI score on a scale of 0- 100 that indicates the importance or criticality of a facility. Because the process to obtain this score is standardized, the result is objective, auditable, and credible. It is based on direct input from the users of the facility. A facility with a high MDI score is indicative of a critical building that needs to be main- 
tained at a high standard in order to minimize the risk of failure and consequent mission disruption. A low MDI score is associated with a building of negligible criticality for which the risk of failure does not directly affect mission. A low MDI score suggests potential for divesture or demolition, especially if the building is in poor condition. By linking facilities to mission, MDI scores communicate a critical and previously missing detail in infrastructure-related decision-making.

This project produced three significant results. First, the general MDI process and interview questions were tailored to be Army-specific by implementing the MDI at a large, complex test installation (White Sands Missile Range). Also, guidance was developed to document best practices for implementing the tailored MDI process at Army installations. Finally, the relation between the MDI process and other Army facility management systems was identified in order to improve the service-wide management of mission-critical facilities.

\section{Benefits}

At both the headquarters and local garrison levels, it is important to understand which facilities are mission-critical, not only for current mission requirements but also for future projected core mission requirements. Although the Army real property database includes an element for denoting mission-critical facilities, this metric is applied subjectively and inconsistently. An Army-specific MDI provides an objective means of measuring the mission dependence on facility infrastructure. The MDI enables installations to determine the relationship between infrastructure and mission, and it provides a credible means for prioritizing sustainment, restoration, and modernization (SRM) requirements for existing facilities and local projects. As a consequence, resource focus is applied to those facilities providing the best military value.

Because the Army has such a large portfolio of building assets, the MDI is well suited to serve as a key measure for objectively allocating limited SRM resources to where they most benefit warfighter capabilities and missions. In addition, MDI information is beneficial in cost-effectively setting the frequency and detail of facility condition assessments, space utilization assessments, and security assessments for the mission-critical buildings based on importance. Finally, the MDI represents a key data element that could be beneficially applied to condition-level standards definition, 
project prioritization, identification of divesture opportunities, and physical security hardening.

Also, the MDI is consistent with the requirements of Executive Order 133327, Federal Real Property Asset Management, which specifically calls for "prioritizing actions to be taken to improve the operational and financial management of the agency's real property inventory." Both the MDI assessment process and the MDI metric support system-wide mission readiness and help to reduce risk by allowing the installation Directorate of Public Works (DPW) and master planning office to focus more closely on the most critical infrastructure. These results ultimately promote better allocation of SRM funding for facilities.

\section{Costs}

A full MDI assessment costs an average of $\$ 1,500$ per mission sub element on the installation. Typically, installations have 25 - 50 mission subelements. Therefore, the cost of a traditional MDI assessment is estimated at $\$ 40 \mathrm{~K}-\$ 75 \mathrm{~K}$ per installation. This cost covers initial mission-toinfrastructure reconnaissance, data analysis, facility operator interviews, and data followup, but does not cover travel. The amount of effort required for an MDI assessment is directly related to the quality and accuracy of information in the installation's real property database.

The cost could be significantly reduced through integration of the MDI survey into the existing Installation Status Report- Infrastructure (ISR-I) facility assessment process by having each ISR-I assessor supply the installation's interruptability and relocatability ratings. Under such an approach, the cost of collecting MDI information is incorporated into the ISR-I assessment. While there is some effort related to training the personnel to provide the interruptability and relocatability ratings, this can be included in the ISR-I training process. That is the recommendation based on the results of this project.

\section{Implementation and maintenance requirements}

In order for the Army to collect MDI information with the least cost and least change to current processes, modifications are necessary to the Army ISR-I criteria to include interruptability and relocatability ratings for each facility. This change would allow for flexible and easy maintenance of data as mission requirements change. 
ISR-I assessors providing the data need proper training in order to produce consistent results. Personnel with extensive training in the MDI interview process can facilitate the initial data gathering effort to ensure the most accurate and consistent results.

MDI information can be stored in the BUILDER Sustainment Management System (SMS) program and used in facility SRM project prioritization. The MDI score, along with the component interruptability and relocatability ratings shall be stored for each facility. The research team also recommends MDI information be added as data elements to the Army's real property database. Because MDI is an indicator of the critical nature of the installation's infrastructure, the information must be appropriately safeguarded and handled as For Official Use Only (FOUO) data.

\section{Recommendations}

The research team recommends that data on facility interruptability and relocatability is collected as part of an annual ISR-I process. This practice would provide the necessary flexibility to rapidly update information as missions change and would make the data collection process less burdensome.

The team also recommends that the first focus of MDI assessment be all tier 1 facilities, then all general support elements at each installation since those have the most interdependence among missions. Such facilities include those supporting fire protection, water distribution, electric service, communications, transportation, DPW, and similar basic support elements. Next, MDI assessment should focus on facilities supporting the direct mission elements for each installation. Administrative facilities, housing facilities, and other general facilities should be defaulted to Army-wide MDI values as appropriate.

It also is recommended that MDI information be stored in the BUILDER SMS for use in facility SRM project prioritization. The MDI score, along with the component interruptability and relocatability ratings, should be stored for each facility. It is recommended MDI information also be added as data elements to the Army real property database. 


\section{Table of Contents}

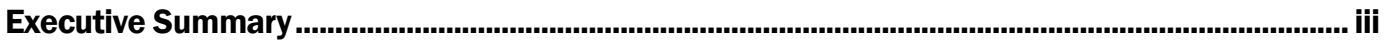

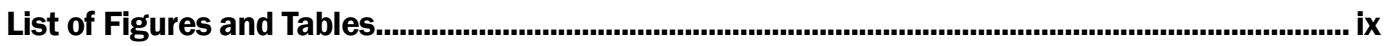

Preface ................................................................................................................................................

Unit Conversion Factors .........................................................................................................

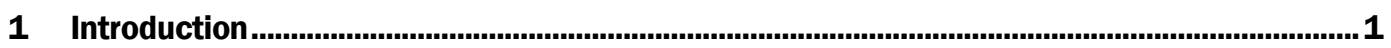

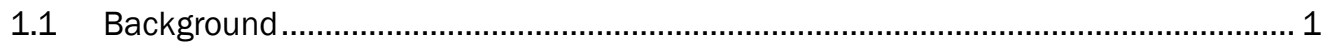

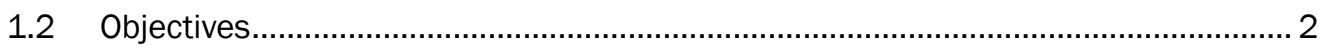

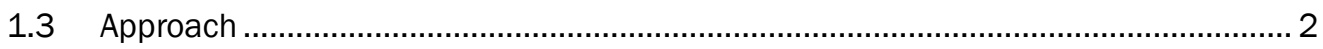

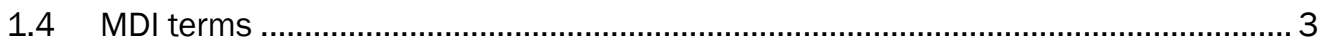

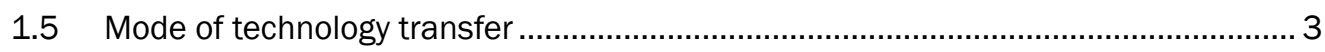

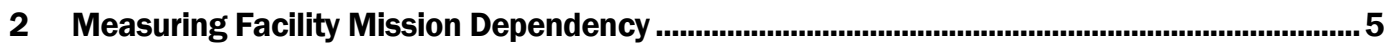

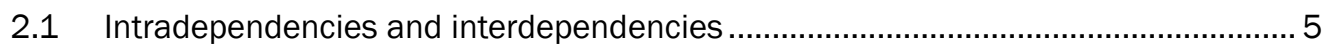

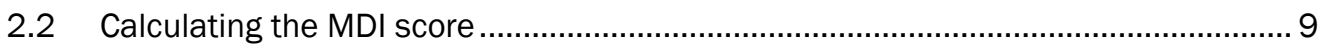

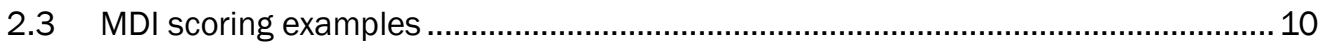

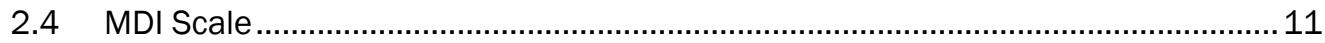

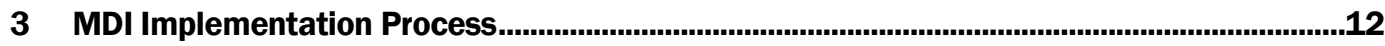

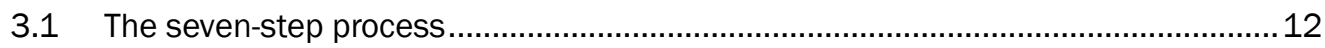

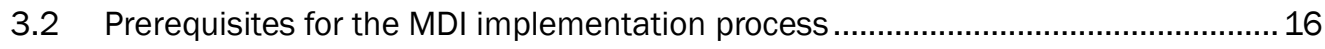

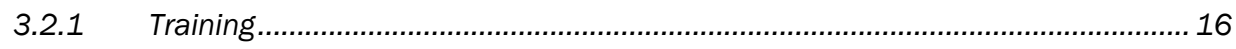

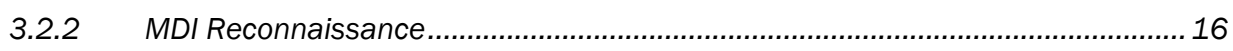

3.2.3 Scheduling interviews................................................................................. 17

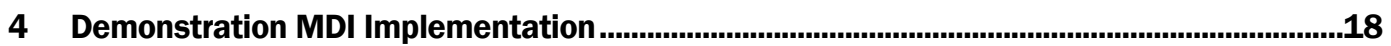

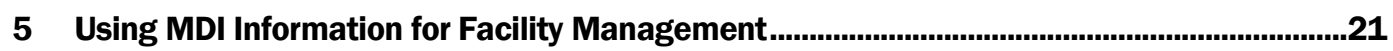

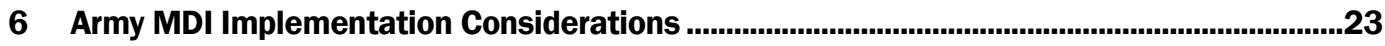

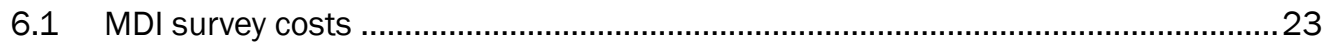

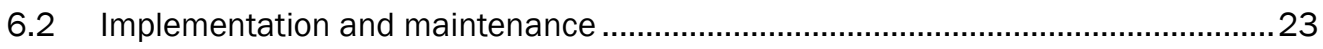

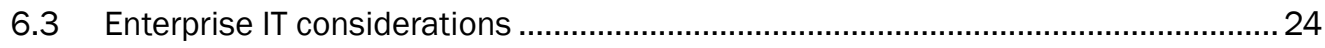

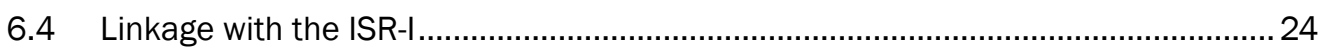

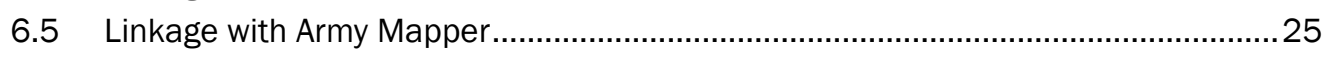

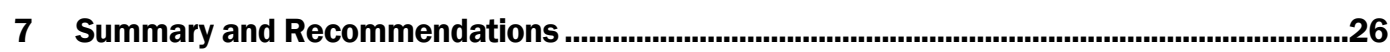

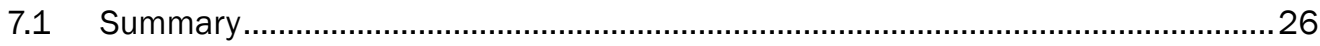

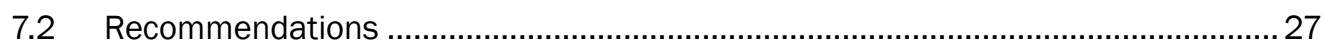

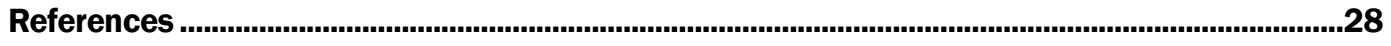




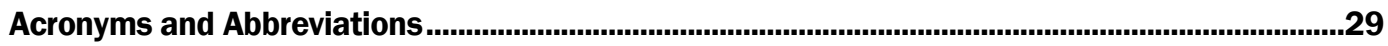

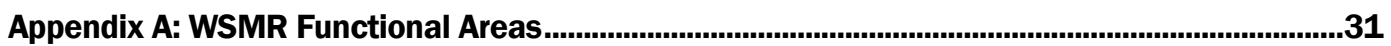

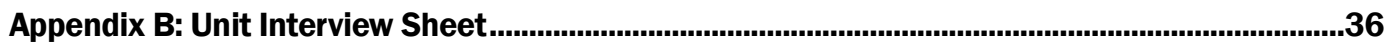

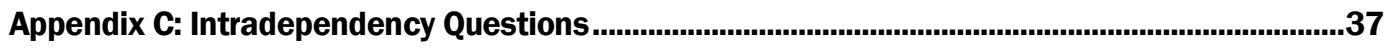

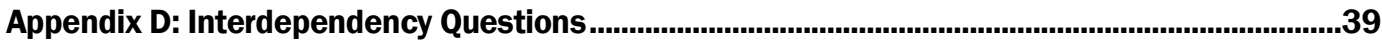

Report Documentation Page 


\section{List of Figures and Tables}

\section{Figures}

Figure 1. Intradependency - mission dependency within a Functional Area, or MDw (NAVFAC ESC 2010).

Figure 2. Interdependency - mission dependency between Functional Areas, or MDb (NAVFAC ESC 2010).

Figure 3. MDI severity scale.

Figure 4. MDI score distribution at WSMR.

\section{Tables}

Table 1. Intradependency (MDw) scoring matrix. .7

Table 2. Interdependency (MDb) scoring matrix. 9

Table 3. WSMR Functional Areas. 19

Table 4. Example facility MDI spreadsheet. 20

Table 5. MDI and Cl correlation matrix. 


\section{Preface}

This study was conducted for the U.S. Army Assistant Chief of Staff for Installation Management (ACSIM) under Installation Technology Transfer Program (ITTP) Project FY09-39, "MDI Methodology." The technical reviewer for ACSIM was Philip Columbus, DAIM-ODF.

The work was performed by the Engineering Processes Branch (CF-N) of the Facilities Division (CF), U.S. Army Engineer Research and Development Center - Construction Engineering Research Laboratory (ERDCCERL). The ITTP Program Manager was Kelly M. Dilks, CEERD-CF-N. At the time of publication, Donald K. Hicks was Chief, CEERD-CF-N; L. Michael Golish was Chief, CEERD-CF; and Martin J . Savoie, CEERD-CV-ZT, was the Technical Director for Installations. The Deputy Director of ERDC-CERL was Dr. Kirankumar Topudurti and the Director was Dr. Ilker Adiguzel.

COL Gary E. J ohnston was the Commander and Executive Director of ERDC, and Dr. J effery P. Holland was the Director.

DISCLAIMER: The contents of this report are not to be used for advertising, publication, or promotional purposes. Citation of trade names does not constitute an official endorsement or approval of the use of such commercial products. All product names and trademarks cited are the property of their respective owners. The findings of this report are not to be construed as an official Department of the Army position unless so designated by other authorized documents. 


\section{Unit Conversion Factors}

\begin{tabular}{|c|c|c|}
\hline Multiply & By & To Obtain \\
\hline acres & $4,046.873$ & square meters \\
\hline cubic feet & 0.02831685 & cubic meters \\
\hline cubic inches & $1.6387064 \mathrm{E}-05$ & cubic meters \\
\hline cubic yards & 0.7645549 & cubic meters \\
\hline degrees (angle) & 0.01745329 & radians \\
\hline degrees Fahrenheit & $(\mathrm{F}-32) / 1.8$ & degrees Celsius \\
\hline feet & 0.3048 & meters \\
\hline gallons (U.S. liquid) & $3.785412 \mathrm{E}-03$ & cubic meters \\
\hline horsepower ( 550 foot-pounds force per second) & 745.6999 & watts \\
\hline inches & 0.0254 & meters \\
\hline miles (U.S. statute) & $1,609.347$ & meters \\
\hline miles per hour & 0.44704 & meters per second \\
\hline pounds (mass) & 0.45359237 & kilograms \\
\hline pounds (mass) per cubic inch & $2.757990 \mathrm{E}+04$ & kilograms per cubic meter \\
\hline square feet & 0.09290304 & square meters \\
\hline square inches & $6.4516 \mathrm{E}-04$ & square meters \\
\hline square yards & 0.8361274 & square meters \\
\hline tons ( 2,000 pounds, mass) & 907.1847 & kilograms \\
\hline yards & 0.9144 & meters \\
\hline
\end{tabular}




\section{Introduction}

\subsection{Background}

The Mission Dependency Index (MDI) is a risk-based metric to link facilities to specific mission elements. The MDI was developed by the Naval Facilities Engineering Command Engineering Service Center (Antelman and Miller 2002) and the U.S. Coast Guard Office of Civil Engineering. It was successfully deployed at Navy, Coast Guard and National Aeronautics and Space Administration (NASA) installations. MDI scores identify the severity of loss of mission-enabling facilities and infrastructure.

This index supports and is consistent with all Federal facility asset management principles, and it is endorsed by the General Services Administration, the National Academy of Sciences' National Research Council, the Federal Facilities Council, the Association of Higher Education Facility Officers (APPA), American Society of Civil Engineering, and the International Facilities Management Association (IFMA).

It uses operational risk management (ORM) techniques of probability and severity and applies them to facilities in terms of interruptability, relocatability, and replaceability. The process of determining an MDI also considers factors such as, environmental hazards, high cost equipment, high personnel occupancy, unique (one of a kind) facilities, emergency facilities, quality of life, and safety.

The MDI also takes into account mission dependencies operating within an organizational component (intradependencies) those operating between or among organizational components (interdependencies). It does this through a structured interview process to capture the "experience, judgment, intuition and situational awareness of local leaders having authority over local operational and facility decisions" (Antelman and Miller 2002). The product of the interviews is a quantitative score normalized over a scale from zero to one hundred, with higher scores representing higher mission dependencies and mission critical facilities.

This assessment tool is powerful and easy to use. Owing to the structured interview process by which data are collected, the MDI procedure returns results that are consistent, repeatable, auditable, and less subjective than 
those produced by ad hoc evaluations. MDI scores communicate a critical and previously missing detail to support infrastructure-related decision making: it links facilities with their related mission elements.

The MDI is consistent with the requirements of Executive Order 133327, Federal Real Property Asset Management, which specifically calls for prioritizing actions to be taken to improve the operational and financial management of the Federal government's real property inventory. It also provides a key component of the Defense Readiness Reporting System (DRRS-A) under Department of Defense Directive DoDD 7730.65.

\subsection{Objectives}

The objective of this project was to tailor the existing MDI process for Army-specific missions, tasks, and facility/ resource capabilities; and to developed guidance for effectively implementing the MDI across Army installations. Tasks supporting those objectives were development of (1) a plan for incorporating MDI data collection into the Army's existing facility assessment process, (2) guidance for using MDI information to improve Army installation facility SRM prioritization and decision support, and (3) a plan to integrate the overall MDI process into the existing Army facility management systems, including those supporting real property, upward condition reporting, and work planning, and GIS.

\subsection{Approach}

The goal of MDI is not to eliminate risk, but to identify risk severity so the mission is accomplished with the minimum amount of loss.

MDI assessments are to be made by the leaders responsible for executing the installation's mission. Their goal is to determine the risk severity of mission-enabling facilities and infrastructure. The assessments include input by the installation Department of Public Works (DPW), which is responsible for managing, maintaining, and sustaining facilities, utilities, infrastructure, and land that directly supports Army missions. Prudence, experience, judgment, intuition and situational awareness of leaders directly involved in the planning and execution of the mission are the critical elements in evaluating the risk severity of mission enabling infrastructure. 


\subsection{MDI terms}

The following terminology is specific to the MDI process:

- Functional Areas - organizational components typically including, but are not limited to, a brigade, battalion, company, platoon, or installation tenant

- Functional Element - facilities and infrastructure occupied or used by a specific Functional Area, including buildings, structures, and utilities

- Intradependency (MDw) - metric for risk severity (in terms of interruptability and relocatability) of Functional Elements or portions thereof (floor or room) within a Functional Area's sphere of control

- Interdependency (MDb) - metric for the degree of reliance (in terms of interruptability and replaceability) of other Functional Areas that provide enabling products or services outside the sphere of their control.

- MDI score - a number ranging from 0-100, with 100 representing the highest risk severity (or impact) to mission

- Risk Severity - an assessment of the expected consequence.

\subsection{Mode of technology transfer}

This project incorporates technology into the BUILDER SMS for future use by Army Department of Public Works (DPW) personnel to manage the criticality of building assets and prioritization of SRM resources.

BUILDER is a fully web-based enterprise software platform which currently supports SQL Server 7.0, 2000, and 2005 (including Express Edition). Support for Oracle is also planned for the near future. All user interface elements run in web browsers using standard HTML and J avaScript. The pilot implementation of the BUILDER database is currently hosted on servers located and supported at ERDC-CERL, Champaign, IL. Wide-scale usage of BUILDER at several Army installations will be transitioned to a centralized data server/ support center as appropriate. The configuration provides fast, secure multiuser access and automatic periodic backups of the Army BUILDER database. BUILDER went through the Department of Defense Information Assurance Certification and Accreditation Process (DIACAP) in J une 2009, and it was granted an Authority to Operate (ATO) by the U.S. Army Information Systems Engineering Command in March 2010. 
Support to Army BUILDER users requiring access to facility functionality information is provided via email or telephone. This support may be provided under the Army's enterprise contract (CHESS) for services. Technical assistance addresses detailed software and how-to questions, diagnoses problems, and documents software errors or bugs to be communicated to the system developer. Periodic onsite support may be required to configure server and database setup of the BUILDER SMS and coordinate IT integration with other Army facility management systems, including HQIIS, Army Mapper, ISR, and GFEBS. Annual user group meetings are planned to help identify and prioritize program enhancements and new features with the input by the user base. 


\section{Measuring Facility Mission Dependency}

\subsection{Intradependencies and interdependencies}

MDI scores are calculated on the basis of responses to four questions. The first two questions evaluate the intradependency of facilities, structures, and utilities used or controlled by each Functional Area (see Figure 1). The first question focuses on the interruptability of a Functional Element. Interruptability is measured in terms of the amount of time before mission capabilities are impacted. The second question addresses the difficulty of relocating the operation or service provided by the Functional Element. The leader(s) directly responsible for the operation or service provided are asked to respond to the following questions:

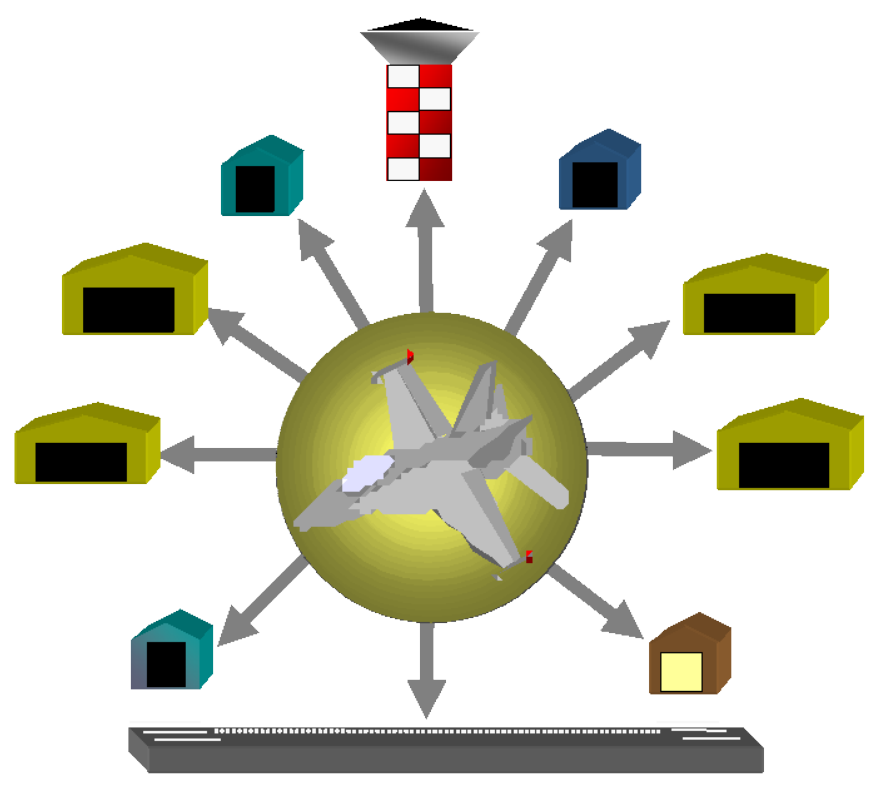

Airfield Operations Group

Figure 1. Intradependency - mission dependency within a Functional Area, or MDw (NAVFAC ESC 2010).

Question 1(Interruptability): How long could the "functions" supported by the (facility, structure, or utility) be stopped without adverse impact to the mission?

I - Immediate (the functions performed within the facility must be maintained continuously (24/7)) 
U - Urgent (minutes, not to exceed 1 hour)

B - Brief (hours, not to exceed 24 hours)

S - Short (days, not to exceed 7 days)

P - Prolonged (weeks, not to exceed 1 month)

E - Extended (1 - 6 months, requires up to 1 week to make operational)

F - Future (6 months, requires up to 1 month to make operational)

M - Mothballed (2+years, requires up to several months to make operational)

D - Demolished (turn-in or demolished, available for use by others).

Question 2 (Relocatability): If your (facility, structure, or utility) is not functional, could you continue performing your mission by using another (facility, structure, or utility), or by setting up temporary facilities?

I - Impossible (an alternate location is not available)

$\mathrm{X}$ - Extremely Difficult (an alternate location exists with minimally acceptable capabilities, but would require either a significant in-house effort (money/man-hours), dislocation of another major occupant, or contracting for additional services and no available contract mechanism is in place to replace the services being provided)

V - Very Difficult (an alternate location exists with marginally acceptable capabilities, but would require either a significant in-house effort (money/man-hours), dislocation of another major occupant, or contracting for additional services and no available contract mechanism is in place to replace the services being provided)

D - Difficult (an alternate location exists with acceptable capabilities and capacity but relocation would require a measurable and unbudgeted level of effort (money/man-hours), but mission readiness capabilities would not be compromised in the process)

$\mathrm{P}$ - Possible (an alternate location is readily available with sufficient capabilities and capacity; in addition the level of effort has been budgeted for or can be easily absorbed). 
The responses to MDI Questions 1 and 2 are entered into Table 1.

Table 1. Intradependency (MDw) scoring matrix.

\begin{tabular}{|c|c|c|c|c|c|c|c|c|c|c|c|c|}
\hline \multicolumn{13}{|c|}{ MISSION INTRA-DEPENDENCY SCORE } \\
\hline & $N$ & \begin{tabular}{|l|} 
Immediat \\
$\mathrm{e}(24 / 7)$
\end{tabular} & $\begin{array}{l}\begin{array}{l}\text { Urgent } \\
(\mathrm{min} / \mathrm{hr})\end{array} \\
\end{array}$ & $\begin{array}{c}\text { Brief } \\
\text { (hrs/day) }\end{array}$ & $\begin{array}{c}\text { Short } \\
\text { (days/week) }\end{array}$ & $\begin{array}{c}\text { Prolonged } \\
\text { (week/month) }\end{array}$ & $\begin{array}{c}\text { Extended } \\
\text { (1-6 months) }\end{array}$ & $\begin{array}{c}\text { Future } \\
(6 \mathrm{mo}-2 \mathrm{yrs}) \\
\end{array}$ & \begin{tabular}{|c|} 
Mothball \\
(2+ years)
\end{tabular} & Historical & Abandoned & \begin{tabular}{|l|} 
Turn-in \\
Demo'd \\
\end{tabular} \\
\hline \multirow{5}{*}{$\begin{array}{c}\text { Q2: } \\
\text { Relocatability }\end{array}$} & Impossible & 80 & 78 & 74 & 68 & 60 & 50 & 40 & 30 & 1.5 & 1 & 0 \\
\hline & $\begin{array}{c}\text { Extremely } \\
\text { Difficult }\end{array}$ & 76 & 72 & 66 & 58 & 48 & 38 & 28 & 20 & 1.5 & 1 & 0 \\
\hline & $\begin{array}{c}\text { Very } \\
\text { Difficult }\end{array}$ & 70 & 64 & 56 & 46 & 36 & 26 & 18 & 12 & 1.5 & 1 & 0 \\
\hline & Difficult & 62 & 54 & 44 & 34 & 24 & 16 & 10 & 6 & 1.5 & 1 & 0 \\
\hline & Possible & 52 & 42 & 32 & 22 & 14 & 8 & 4 & 2 & 1.5 & 1 & 0 \\
\hline
\end{tabular}

MDI Questions 3 and 4 evaluate the interdependency between each Functional Area and other installation Functional Areas providing essential operational support or services (see Figure 2). Question 3 focuses on interruptability of operational support or services provided by other installation Functional Areas. Interruptability is measured in terms of time before mission capabilities are impacted. Question 4 focuses on the "ability or difficulty" to replace or replicate the services with another provider from any source.

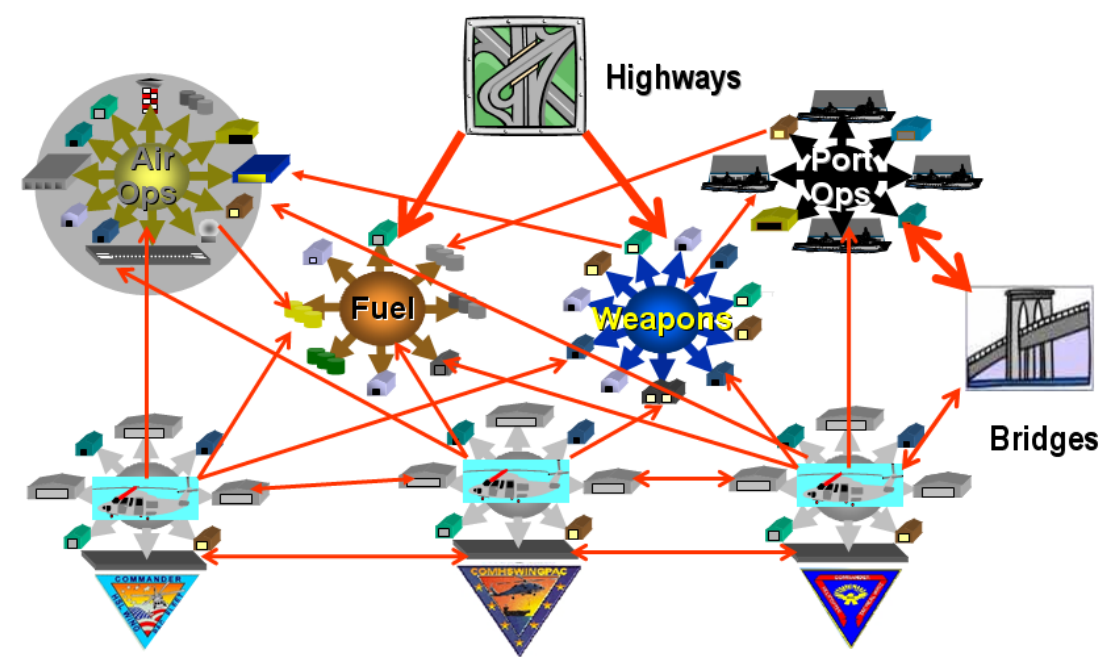

Figure 2. Interdependency - mission dependency between Functional Areas, or MDb (NAVFAC ESC 2010). 
Question 3 (Interruptability): How long could the services provided by (named functional Area) be interrupted before impacting your mission readiness?

I - Immediate (Any interruption will instantly impact mission readiness)

U - Urgent (minutes, not to exceed 1 hour)

B - Brief (minutes or hours, not to exceed 24 hours and there are insufficient redundancies built into the system to absorb a brief interruption)

S - Short (days, not to exceed 7 days, but there are sufficient and effective redundancies built into the system to cover brief interruptions)

P - Prolonged (weeks, not to exceed 1 month)

E - Extended (1 - 6 months)

F - Future (6 months - 2 years).

Question 4 (Replaceability): How difficult would it be to replace or replicate the services provided by (named Functional Area) with another provider from any source?

I - Impossible (there are no known redundancies or excess/ surge capacities available, or there are no viable commercial alternatives - only this site/ command can provide these services)

$\mathrm{X}$ - Extremely Difficult (there are minimally acceptable redundancies or excess/ surge capacities available, or there are viable commercial alternatives, but no readily available contract mechanism in place to replace the services)

V - Very Difficult (there are marginally acceptable redundancies or excess/ surge capacities available, or there are viable commercial alternatives, but no readily available contract mechanism in place to replace the services)

D - Difficult (services exist and are available, but the form of delivery is ill defined or will require a measurable and unbudgeted level of effort to obtain (money/ man-hours), but mission readiness capabilities would not be compromised in the process)

P - Possible (services exist, are available, and are well defined). 
The responses to MDI Questions 3 and 4 are entered into Table 2, as shown below.

Table 2. Interdependency (MDb) scoring matrix.

\begin{tabular}{|c|c|c|c|c|c|c|c|c|}
\hline \multicolumn{9}{|c|}{ MISSION INTER-DEPENDENCY SCORE } \\
\hline & & \multicolumn{7}{|c|}{ Q3: Interruptability } \\
\hline & & $\begin{array}{l}\text { None } \\
(24 / 7)\end{array}$ & $\begin{array}{l}\text { Urgent } \\
(\mathrm{min} / \mathrm{hr})\end{array}$ & $\begin{array}{c}\text { Brief } \\
\text { (hrs/day) }\end{array}$ & $\begin{array}{c}\text { Short } \\
\text { (days/week) }\end{array}$ & $\begin{array}{c}\text { Prolonged } \\
\text { (week/month) }\end{array}$ & $\begin{array}{c}\text { Extended } \\
(1-6 \text { months })\end{array}$ & $\begin{array}{c}\text { Future } \\
\text { (6 mo }-2 \text { yrs) }\end{array}$ \\
\hline \multirow{5}{*}{$\begin{array}{c}\text { Q4: } \\
\text { Relocatability }\end{array}$} & Impossible & 20.0 & 18.0 & 16.0 & 14.0 & 12.0 & 10.0 & 8.0 \\
\hline & $\begin{array}{l}\text { Extremely } \\
\text { Difficult }\end{array}$ & 18.0 & 16.0 & 14.0 & 12.0 & 10.0 & 8.0 & 6.0 \\
\hline & $\begin{array}{l}\text { Very } \\
\text { Difficult }\end{array}$ & 16.0 & 14.0 & 12.0 & 10.0 & 8.0 & 6.0 & 4.0 \\
\hline & Difficult & 14.0 & 12.0 & 10.0 & 8.0 & 6.0 & 4.0 & 2.0 \\
\hline & Possible & 12.0 & 10.0 & 8.0 & 6.0 & 4.0 & 2.0 & 00 \\
\hline
\end{tabular}

\subsection{Calculating the MDI score}

The scoring matrices shown in Tables 1 and 2 are used in conjunction with the MDI algorithm to calculate the MDI score. Using a matrix to quantify and prioritize risk severity does not eliminate the inherently subjective nature of risk assessment; however, a matrix does provide a consistent framework for evaluating risk. While the degree of risk severity is subjective in nature, the matrix does accurately reflect the relative amount of perceived risk severity by leaders responsible for mission execution (subject matter experts).

Army MDI Algorithm: MDI scores are determined using the following weighted algorithm:

$$
\mathrm{MDI}=\mathrm{MDw} \times(1+(\mathrm{MDb} \text { avg }+\operatorname{Ln}(\mathrm{n})) / 100)
$$

where

MDI $=$ Mission Dependency Index normalized from 0 to 100

MDw = Intradependency Score; response to questions 1 and 2 (see

Table 1). 
MDb ave $=($ Interdependency Score) : The average response to questions 3 and 4, see Table 2, from other Functional Areas, in regards to the Functional Area whose MDI is being calculated.

Ln( ) = natural $\log$ function of $\mathrm{n}$

$\mathbf{n}=$ number of Interdependencies with other Functional Areas

The fourth scoring component of MDI is the value " $n$ " which is the number of Functional Areas identifying interdependency. The number of Functional Areas varies substantially from small to large installations.

The natural log function is used because the value of " $\mathrm{n}$ " is constrained, and diminishes as " $n$ " increases (Air Force Instruction 90-901, 1 April 2000). The intradependency and interdependency components of the overall MDI score are weighed as follows: $\mathrm{MDw}=80 \%$, MDb Average $=$ $20 \%$. This is done by the interdependency amplification factor (1+(MDb Average $+\operatorname{Ln}(n)$ ) / 100), which can increase the final MDI value over the MDw value by a factor of $1.00-1.25$. This means MDI scores are mostly dependent on the subcomponent's knowledge of its facilities (intradependency). Additionally, MDw and MDb have been weighted toward interruptability questions 1 and 3 by a factor of 60/40. This is done because questions related to interruptability are believed to be more objective than questions related to relocatability and replaceability.

\subsection{MDI scoring examples}

MDI limits operators to 80 points out of 100 when scoring the impact of infrastructure controlled or used by their Functional Area (MDw, intradependence). This limit assumes that no operator's Functional Area is critical unless other operators are dependent on the operations or services (mission enabling) they provide (MDb, interdependence).

Totally independent Functional Areas providing no support to other installation Functional Areas are limited to a maximum interdependency (MDw) score of 80 (exactly at critical breakpoint, as seen in Figure 3). Therefore, only a 24/ 7 operating facility that is impossible to relocate is critical unless the facility were to receive high interdependency scores from other Functional Areas. 


\subsection{Scale}

The scoring nomenclature is divided into five categories, with 15 - 20 point spreads separating the critical, significant, relevant, and moderate levels. The MDI equation is weighted to allow Functional Elements with high interdependency scores to move up to the next level of criticality.

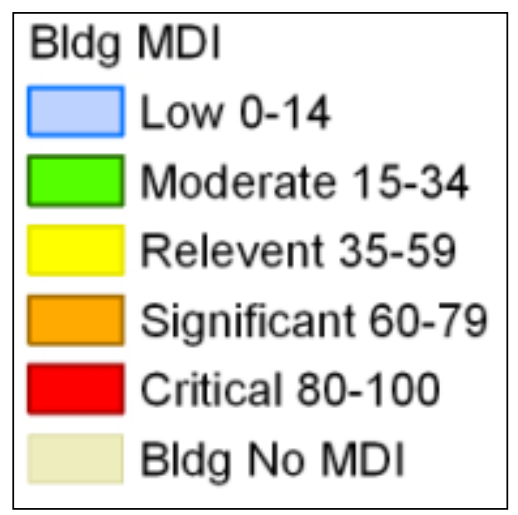

Figure 3. MDI severity scale. 


\section{MDI Implementation Process}

\subsection{The seven-step process}

The MDI is implemented using a seven-step process. MDI assessments are to be made by the leader or leaders responsible for executing the mission. He or she is responsible for determining the risk severity of missionenabling facilities and infrastructure. Prudence, experience, judgment, intuition, and situational awareness of leaders directly involved in the planning and execution of the mission are the critical elements in evaluating the risk severity of mission enabling infrastructure. A description of the seven-step process follows.

\section{Step 1 - Identify Functional Areas}

Functional areas are composed of two major groupings:

- Host Functional Areas, typically including Operating Forces Support, Community Support, and Base Support

- Tenants.

\section{Step 2 - Identify Functional Elements}

Functional Elements are Facilities and Infrastructure occupied or used by a Functional Area.

\section{Step 3 - Assess Intradependency}

For each Functional Element (facility or infrastructure) within a Functional Area, answer the following two questions:

Question 1(Interruptability): How long could the "functions" supported by the (facility, structure, or utility) be stopped without adverse impact to the mission?

I - Immediate (the functions performed within the facility must be maintained continuously (24/7))

U - Urgent (minutes, not to exceed 1 hour)

B - Brief (hours, not to exceed 24 hours) 
S - Short (days, not to exceed 7 days)

P - Prolonged (weeks, not to exceed 1 month)

E - Extended (1 - 6 months, requires up to 1 week to make operational)

F - Future (6 months, requires up to 1 month to make operational)

M - Mothballed (2+years, requires up to several months to make operational)

D - Demolished (Turn-in or Demolished, available for use by others).

Question 2 (Relocatability): If your (facility, structure, or utility) is not functional, could you continue performing your mission by using another (facility, structure, or utility), or by setting up temporary facilities?

I - Impossible (an alternate location is not available)

X - Extremely Difficult (an alternate location exists with minimally acceptable capabilities, but would require either a significant in-house effort (money/man-hours), dislocation of another major occupant, or contracting for additional services and no available contract mechanism is in place to replace the services being provided)

V - Very Difficult (an alternate location exists with marginally acceptable capabilities, but would require either a significant in-house effort (money/man-hours), dislocation of another major occupant, or contracting for additional services and no available contract mechanism is in place to replace the services being provided)

D - Difficult (an alternate location exists with acceptable capabilities and capacity but relocation would require a measurable and unbudgeted level of effort (money/man-hours), but mission readiness capabilities would not be compromised in the process)

$\mathrm{P}$ - Possible (an alternate location is readily available with sufficient capabilities and capacity; in addition the level of effort has been budgeted for or can be easily absorbed).

\section{Step 4 - Assess Interdependency}

For each identified Functional Area, answer the following two questions: 
Question 3 (Interruptability): How long could the services provided by (named functional Area) be interrupted before impacting your mission readiness?

I - Immediate (any interruption will instantly impact mission readiness)

U - Urgent (minutes, not to exceed 1 hour)

B - Brief (minutes or hours, not to exceed 24 hours and there are insufficient redundancies built into the system to absorb a brief interruption)

S - Short (days, not to exceed 7 days, but there are sufficient and effective redundancies built into the system to cover brief interruptions)

P - Prolonged (weeks, not to exceed 1 month)

E - Extended (1 - 6 months)

F - Future (6 months - 2 years).

Question 4 (Replaceability): How difficult would it be to replace or replicate the services provided by (named functional Area) with another provider from any source?

I - Impossible (there are no known redundancies or excess/ surge capacities available, or there are no viable commercial alternatives - only this site/ command can provide these services)

$\mathrm{X}$ - Extremely Difficult (there are minimally acceptable redundancies or excess/ surge capacities available, or there are viable commercial alternatives, but no readily available contract mechanism in place to replace the services)

V - Very Difficult (there are marginally acceptable redundancies or excess/ surge capacities available, or there are viable commercial alternatives, but no readily available contract mechanism in place to replace the services)

D - Difficult (services exist and are available, but the form of delivery is ill defined or will require a measurable and unbudgeted level of effort to obtain (money/ man-hours), but mission readiness capabilities would not be compromised in the process)

P - Possible (services exist, are available, and are well defined). 


\section{Step 5-Calculate preliminary MDI scores}

A scoring matrix is used to accomplish the fifth step of the MDI process. Using a matrix to quantify and prioritize risk severity does not reduce the inherently subjective nature of risk assessment, but it does provide a consistent framework for evaluating risk. While the degree of risk severity is subjective in nature, the matrix does accurately reflect the relative amount of perceived risk severity by leaders responsible for mission execution (who are subject matter experts). Using the matrix below, Intradependency (MDw) and Interdependency (MDb) scores are expressed as a number.

MDI scores are determined using the following weighted algorithm:

$$
\mathbf{M D I}=\mathbf{M D w}+(1+(\mathbf{M D b} \text { avg }+\operatorname{Ln}(\mathbf{n})) / 100)
$$

where

MDI $=$ Mission Dependency Index normalized from 100-0

$\mathrm{MDw}=($ Intradependency Score $)$ : Response to questions 1 and 2, see Table 1.

$\mathrm{MDb}$ ave $=$ (Interdependency Score): The average response to questions 3 and 4 from other Functional Areas, in regards to the Functional Area of the facility whose MDI is being calculated.

$\mathrm{Ln}($ ) = natural $\log$ function of $\mathrm{n}$

$\mathrm{n}=$ number of Interdependencies with other Functional Areas

Facilities or infrastructure (Functional Elements) classified as vacant or abandoned are assigned an MDI score of 1 .

Facilities or infrastructure unclaimed (i.e., orphan facility) by an installation Functional Area or scheduled for demolition are assigned an MDI score of 0 .

\section{Step 6 - Review MDI score accuracy}

MDI scores are reviewed by each Functional Area mission commander and the installation commander for accuracy and completeness. 
Step 7 - Save data to facility real property database

The MDI score and date of survey are entered into BUILDER Sustainment Management System to be associated with facility real property file.

\subsection{Prerequisites for the MDI implementation process}

\subsubsection{Training}

Training requirements for MDI interview personnel are recommended as follows:

- one day for a training workshop

- a half-day to observe the interview process.

- a half-day of conducting an interview under the supervision of a skilled interviewer.

\subsubsection{Reconnaissance}

This prerequisite involves a visit to the installation to brief the DPW and garrison commander. In order to collect the information needed for MDI implementation, the following tasks are accomplished:

- Identify all relevant host installation Functional Areas using a standardized list.

- Identify all tenant Commands.

- Establish a survey date.

- Request that the garrison command contact all host Functional Areas and tenants and schedule interview appointments (a 20- to 40-hour effort depending on the size of the installation).

- Request that the installation senior commander send out an e-mail asking for cooperation and assistance in completing the MDI survey.

- Acquire installation maps and telephone directory.

- Identify a Public Works point of contact to provide assistance during the survey.

- Request a survey team space with a telephone and computer.

- Prepare MDI survey forms by downloading facilities data from the Army Real Property Inventory to the forms (a 5 - 8 day effort depending on the size of the installation and number of Functional Areas). 


\subsubsection{Scheduling interviews}

MDI interviews require the assistance of one person to schedule appointments and act as a point of contact during the survey. Each Functional Area interviewed must provide one or more leaders (Commanding Officer, Executive Officer, senior enlisted noncommissioned officer, or senior civilian to speak knowledgeably about the mission, mission-enabling infrastructure, and interdependencies with other missions on and off the installation) for each Functional Area interview. Interviews typically take approximately 45 minutes to complete, depending on the number of assets associated with each Functional Element. 


\section{Demonstration MDI Implementation}

White Sands Missile Range (WSMR), NM, was selected as a demonstration installation for MDI to show that the MDI can effectively be used to document mission dependencies for highly complex operations. WSMR hosts a number of testing operations for different DoD components, and as such it has a large number of Functional Areas and tenants. DPW personnel at the installation assisted in the MDI process to identify all Functional Areas at the installation. The following information was used to identify Functional Elements controlled or used by each Functional Area:

- White Sands real property information

- installation telephone directory

- the Installation Geospatial Information and Services (IGI\&S) database.

A total of 38 Functional Areas, 19 hosts, and 19 tenants were identified for survey (see Appendix A). Table 3 shows an example breakdown of the Functional Areas (missions) at WSMR.

Figure 4 shows the distribution of MDI scores at WSMR. A total of 855 Functional Elements (facilities were rated). The MDI survey was conducted by a survey team consisting of three experienced Navy MDI surveyors. Surveyors were also observed and assisted by ERDC-CERL and WSMR personnel. 
Table 3. WSMR Functional Areas.

\begin{tabular}{|c|c|c|c|}
\hline Code & Functional Area & \#Facilities & Group \\
\hline TEDT-WS-CG & Office of the Commanding General & 2 & Command \\
\hline TEDT-WS-CS & Chief of Staff, Plans \& Operations & & Command \\
\hline TEDT-WS-JA & Staff Judge Advocate & & Command \\
\hline TEDT-WS-IG & Inspector General & & Command \\
\hline TEDT-WS-PA & Public Affairs & 2 & Command \\
\hline TEDT-WS-RM & Resource Management Directorate & 1 & Command \\
\hline TEDT-WS-TC & Commander, White Sands Test Center & & Command \\
\hline TEDT-WS-0,0S,SO,G & Operations G3, Personnel, Logistics, Environmental, Secu & Safety, Site Def & Command \\
\hline IMWE-WSM-ZA & Office of the Garrison Commander & 2 & Command \\
\hline IMWE-WSM-HR & Human Resources & & \\
\hline IMWE-WSM-PAI & Plans, Analysis \& Integration & 1 & Command \\
\hline TEDT_WSD & Data Sciences Directorate & 74 & DSD \\
\hline TEDT-WSD-P & Data Processing Division & & DSD \\
\hline TEDT-WSD-P & Applied Software, Data Management, Real Time & & DSD \\
\hline TEDT-WSD-D & Distributed Systems Division & & DSD-Net \\
\hline TEDT-WSD-D & inter-RangeControl Center & & DSD-Net \\
\hline TEDT-WSD-D & Network & & DSD-Net \\
\hline TEDT-WSD-D & LMR/Radio & & DSD-Net \\
\hline TEDT-WSD-I & information Management Div & & DSD \\
\hline TEDT-WSD-I & Telephone & & DSD-Tele \\
\hline TEDT-WSD-I & Email & & DSD \\
\hline TEDT-WSD-I & Data/File/App/Financial/GIS/Collaboration/Web Servers & & DSD \\
\hline IMWE-WSM-SD & Law Enforcement \& Security Dir & & \\
\hline IMWE-WSM-SD & Law Enforcement Div & 42 & DES \\
\hline IMWE-WSM-SD & Security Counter intelligence Div & 1 & DIS \\
\hline IMWE-WSM-PW-Fire & Fire \& Emergency Services Div & 27 & Fire \\
\hline IMWE-WSM-MW & Dir. Community Activities \& Housing & 63 & MWR \\
\hline IMWE-WSM-CH & Staff Chaplain & 3 & Chaplain \\
\hline TEDT-WSM & Materiel Test Directorate & 494 & MTD \\
\hline TEDT-WSM-T & Missiles \& Space Din & & MTD \\
\hline TEDT-WSM-F & Future Force Div & & MTD \\
\hline TEDT-WSM-O & Systems Performance \& Assessment Div & & MTD \\
\hline
\end{tabular}

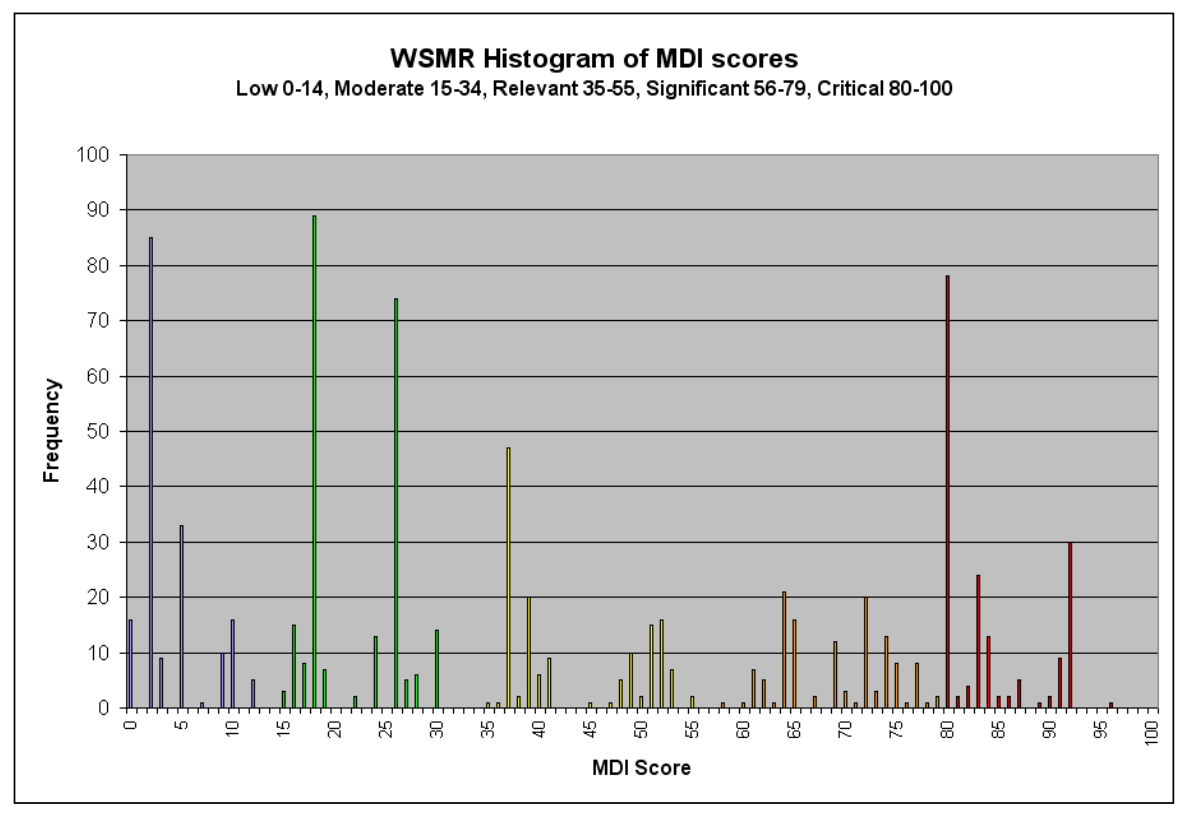

Figure 4. MDI score distribution at WSMR. 
Example results by facility are provided in Table 4.

Table 4. Example facility MDI spreadsheet.

\begin{tabular}{|c|c|c|c|c|c|c|c|c|c|c|c|}
\hline Interview & Site & Fac No. & Facility Name & Comments & Q1 & Q2 & MDw & Group & MDb avg & $\mathbf{n}$ & MDI \\
\hline 10-LOG & MAIN POST & 01775 & VEHICLE FUEL STORAGE TANKAG & & I & $\mathbf{P}$ & 52 & Logis.POL & 14.7 & 3 & 61 \\
\hline 10-LOG & MAIN POST & 01779 & MTR POOL \#1 DIESEL STR TK & & I & $\mathbf{P}$ & 52 & Logis-POL & 14.7 & 3 & 61 \\
\hline 10-LOG & MAIN POST & 01781 & GAS STR TNK IN MOTOR POOL \#1 & & I & $\mathbf{P}$ & 52 & Logis.POL & 14.7 & 3 & 61 \\
\hline 10-LOG & MAIN POST & 01785 & GAS STATION W/GUILDING & DATA STORAGE FOR REFUELER & B & D & 44 & Logis-POL & 14.7 & 3 & 51 \\
\hline 10-LOG & MAIN POST & 01785 & GAS STATION W/BUILDING & & B & D & 44 & Logis-POL & 14.7 & 3 & 51 \\
\hline 10-LOG & MAIN POST & 01793 & DIESEL OIL STORAGE AG & & I & $\mathbf{P}$ & 52 & Logis.POL & 14.7 & 3 & 61 \\
\hline 10-LOG & MAIN POST & 01876 & POL DIESEL STORAGE TANK & $25,000 \mathrm{GAL}$ & B & D & 44 & Logis.POL & 14.7 & 3 & 51 \\
\hline 10-LOG & MAIN POST & 01877 & POL DIESEL STORAGE TANK & 25,000 GAL UNLEADED & B & D & 44 & Logis.POL & 14.7 & 3 & 51 \\
\hline 10-LOG & MAIN POST & 01878 & POL DIESEL OIL STORAGE TANK & 25,000 GAL UNLEADED & B & D & 44 & Logis-POL & 14.7 & 3 & 51 \\
\hline 10-LOG & MAIN POST & 01879 & LP GAS BULK STORAGE AG & 25,000 GAL UNLEADED & B & D & 44 & Logis-POL & 14.7 & 3 & 51 \\
\hline 10-LOG & HOLLOMAR & 29695 & GAS STATION W/BUUILDING & HOLLOMAN & $\mathrm{D}$ & $\mathrm{P}$ & $\mathbf{0}$ & Logis-POL & 14.7 & 3 & 0 \\
\hline 10-LOG & HOLLOMAR & 29696 & VEHICLE FUEL STORAGE TANKAG & HOLLOMAN & D & $\mathrm{P}$ & $\mathbf{0}$ & Logis.POL & 14.7 & 3 & 0 \\
\hline 10-LOG & HOLLOMAR & 29697 & VEHICLE FUEL STORAGE TANKAG & HOLLOMAN & $\mathrm{D}$ & $\mathrm{P}$ & $\mathbf{0}$ & Logis.POL & 14.7 & 3 & 0 \\
\hline 10-LOG & RHODES C & 30725 & GAS STATION W/BUILDING & MIDPOINT FUEL & B & D & 44 & Logis.POL & 14.7 & 3 & 51 \\
\hline 10-LOG & RHODES C & 30760 & DIESEL OIL STR - POL & ABOVEGROUND & B & D & 44 & Logis-POL & 14.7 & 3 & 51 \\
\hline 10-LOG & RHODES C & 30762 & VEH FUEL STOR - POL & ABOVEGROUND & B & D & 44 & Logis.POL & 14.7 & 3 & 51 \\
\hline 10-LOG & STALLION & 34204 & POL DIESEL OIL STORAGE TANK & & B & D & 44 & Logis·POL & 14.7 & 3 & 51 \\
\hline 10-LOG & STALLION & 34205 & POL DIESEL OIL STORAGE TANK & & B & D & 44 & Logis-POL & 14.7 & 3 & 51 \\
\hline 10-LOG & STALLION & 34207 & POL VEH FUEL STORAGE & $25,000 \mathrm{GAL}$ & B & D & 44 & Logis.POL & 14.7 & 3 & 51 \\
\hline 10-LOG & STALLION & 34210 & GAS STATION W/EUILDING & & B & D & 44 & Logis.POL & 14.7 & 3 & 51 \\
\hline 10-LOG & & 00314 & SCALE HOUSE & & $\mathbf{S}$ & $\mathbf{P}$ & 22 & Logis-Trans & 6.7 & 3 & 24 \\
\hline 10-LOG & & 01709 & CAR WASH & & $\mathbf{S}$ & $\mathbf{P}$ & 22 & Logis-Trans & 6.7 & 3 & 24 \\
\hline 10-LOG & MAIN POST & 01752 & ST CLEAN FAC & & $\mathrm{D}$ & $\mathrm{P}$ & $\mathbf{0}$ & Logis-Trans & 6.7 & 3 & 0 \\
\hline 10-LOG & MAIN POST & 01753 & HEAW EQUIP MAINT SHOP & & $\mathbf{S}$ & $\mathbf{P}$ & 22 & Logis-Trans & 6.7 & 3 & 24 \\
\hline 10-LOG & MAIN POST & 01776 & BATTERY SHOP & & $\mathbf{S}$ & $\mathbf{P}$ & 22 & Logis-Trans & 6.7 & 3 & 24 \\
\hline
\end{tabular}

Each data element (represented in the column headings) is defined below:

- Interview - the Functional Area Interview associated with each facility

- Site - the physical location of the facility on base

- Fac No - The Facility Number from Real Property Inventory

- Facility Name - The Facility Name Descriptor

- Comments - Comments appended during interview to better describe facility (helps improve quality of real property information)

- Q1 - Answer to Question 1 (Intradependency/ Interruptability)

- Q2 - Answer to Question 2 (Intradependency/ Relocatability)

- MDw - Interdependency Score

- Group - Service Group for Interdependency

- $\mathrm{MDb}$ avg - Additional score for interdependency

- $\mathrm{n}$ - number of dependent missions

- MDI - overall facility Mission Dependency Index (MDI) score. 


\section{Using MDI Information for Facility Management}

Executive Order 13327, Federal Real Property Asset Management, mandates the promotion of the efficient and economical use of property assets. Changing requirements have driven the need to optimize capital assets and to develop a systematic approach to prioritize actions needed to improve the operational and financial management of the agency's real property inventory.

MDI measures the severity of loss of mission as a function of interruptability and relocatability/ replaceability. However, MDI does not quantify the probability of infrastructure failure. Probability of infrastructure failure is determined by condition, which is measured by a Condition Index (CI). If severity is quantitatively determined using MDI and failure probability by using a CI, then risk to the mission may be expressed through the following formula:

$$
\text { Risk }=\text { Probability } x \text { Severity }
$$

ERDC-CERL developed the CI as a key element of PAVER, ROOFER, and BUILDER SMS processes for facility condition assessment and capital planning. As shown in Table 5, CI is a condition measured on a $0-100$ scale with 15-point intervals. Likewise MDI is normalized to a 0-100 scale with 15-point intervals. A low facility CI number is an indicator of increased probability of infrastructure or system failure. 
Table 5. MDI and Cl correlation matrix.

\begin{tabular}{|l|l|l|}
\hline \multirow{2}{*}{ Cl (Probability of Failure) } & Score & MDI (Risk Severity) \\
\hline \multirow{2}{*}{ Low } & 100 & Critical \\
\hline \multirow{3}{*}{ Moderate } & 85 & Significant \\
\hline \multirow{3}{*}{ High } & 70 & Relevant \\
\cline { 2 - 2 } & 55 & Moderate \\
\cline { 2 - 2 } & 40 & \multirow{3}{*}{ Low } \\
\hline
\end{tabular}

The MDI process is a decision-support tool to be used by facility engineering personnel at all levels to increase installation operational effectiveness by identifying critical installation infrastructure. When combined with other facility-support metrics, MDI can be used to

- determine Sustainment, Restoration, and Modernization (SRM) project prioritization

- determine depth and frequency of facility condition assessments

- determine DPW execution response time

- identify facility divestiture or modernization opportunities

- identify and validate Anti-Terrorism/Force Protection (ATFP) projects and other specialized projects. 


\section{Army MDI Implementation Considerations}

This chapter covers issues to be considered for effective implementation of the MDI throughout the Army. It includes discussion of changes that would need to be made in order to promote a cost-effective, well integrated process.

\subsection{MDI survey costs}

The cost for a full MDI assessment at an installation averages approximately \$1,500 per mission sub-element hosted. An installation typically has 25 - 50 mission sub-elements, so a standard MDI assessment is estimated at $\$ 40,000-\$ 60,000$ per installation. This includes initial mission-to-infrastructure reconnaissance, data analysis, facility operator interviews, and data follow-up, but does not include travel. The effort involved in an MDI assessment is directly related to the quality and accuracy of information in the installation's real property database.

One option to considerably reduce cost would be to integrate the MDI assessment into the existing Installation Status Report- Infrastructure (ISRI) facility assessment process by having each ISR-I assessor supply the installation's interruptability and relocatability ratings. Under such an approach, the cost of collecting MDI information is incorporated into the ISR-I assessment. While there is some effort related to training the personnel to provide the interruptability and relocatability ratings, that can be included in the ISR-I training process.

\subsection{Implementation and maintenance}

In order for the Army to accomplish the collection of MDI information most cost effectively and with the least change to existing Army processes, ISR-I criteria would need to be modified to include the interruptability and relocatability ratings for each facility. This modification would promote flexible and easy maintenance of data as mission requirements change.

The ISR-I assessors providing the data require proper training to achieve consistent results. Personnel previously trained extensively in the MDI in- 
terview process should facilitate the initial data gathering effort to assure the most accurate and consistent results.

MDI information should be stored in the BUILDER SMS program for use in facility SRM project prioritization. The MDI score, along with the component interruptability and relocatability ratings, should be stored for each facility. It is recommended that MDI information also be added as data elements to the Army's real property database. Because MDI is an indicator of the critical nature of an installation's infrastructure, the information must be appropriately safeguarded and stamped For Official Use Only (FOUO).

\subsection{Enterprise IT considerations}

The details of the MDI surveys should be stored in the BUILDER SMS for analysis of facility metrics to be used in SRM planning. BUILDER uses an open data architecture that enables free communication with other electronic Army management systems and data repositories. These communication links are created using web services and XML exchange features. To effectively improve integration with other Army systems that manage and report facility information, this information exchange needs to be robust and seamless.

BUILDER is able to provide the following capacities for MDI management:

- Calculate default MDI scores based on catcode.

- Provide a repository for MDI survey information.

- House a list of typical installation Functional Areas

- Provide a procedure for changing an existing MDI score for a facility through the ISR-I assessment process.

It should be noted that MDI scores are time dependent, and they may be impacted by a change in mission, increased mission tempo, infrastructure availability, capacity, condition, and functionality. BUILDER provides a process to accommodate these time-dependent changes.

\subsection{Linkage with the ISR-I}

Army installations report the condition and readiness of their facilities using the Installation Status Report-Infrastructure (ISR-I). Building tenants 
are primarily responsible for providing a condition/readiness rating based on standardized guidelines that consider several different aspects of the facility. While the ISR-I assessment process attempts to identify facility requirements affecting readiness and mission, there is not a formalized process to incorporate mission interruptability and relocatability into the rating. By linking those mission metrics to the ISR-I, Army installations will be able to collect data and evaluate priorities for their existing buildings based on mission criticality. With ISR-I information feeding into BUILDER, information updates to the real property database will be readily available for planning purposes.

\subsection{Linkage with Army Mapper}

Army Mapper provides enterprise-wide GIS support. It is a geographic data repository for all base-related infrastructures to be used for master planning purposes. The open architecture of BUILDER allows for linkage and integration of Army Mapper data tables with BUILDER. Such integration would allow for building information, displayed from building footprint shapefiles, to be overlaid with other infrastructure domains such as pavements, railroads, airfield, and other utilities, to provide a comprehensive view of the installation in native GIS data architecture. 


\section{Summary and Recommendations}

\subsection{Summary}

The Mission Dependency Index (MDI) was developed to provide a key measure for the objective allocation of SRM resources to infrastructure assets in order to provide maximum benefit to the warfighting mission. MDI data also are well suited for cost-effectively setting the frequency and detail of facility condition assessments, space utilization assessments, and security assessments for mission-critical buildings based on rating. Finally, the MDI represents a key data element that could be beneficially applied to condition-level standards definition, project prioritization, identification of divesture opportunities, and physical security hardening. Both the MDI assessment process and MDI metric support system-wide mission readiness. They help to reduce risk by allowing the installation to focus more directly on the most critical infrastructure. These benefits ultimately promote better allocation of SRM funding for facilities.

The information needed to calculate the MDI metric is generated through interviews with operations and facility decision makers who are the most authoritative subject-matter experts on their installation's infrastructure. These interviews are the basis for identifying infrastructure-dependent missions and each facility's interruptability and relocatability with respect to their missions. Interruptability indicates how long facility operations could be interrupted without adverse mission impact, and relocatability indicates how readily operations could be relocated to avoid adverse impact. After missions have been identified and facilities have been evaluated for interruptability and relocatability, the MDI process assesses mission interdependencies. An interdependency is a measure of one mission's output on the execution of a different mission.

An MDI score, using a rating scale of $0-100$ that is analogous to indices created by Sustainment Management Systems (SMSs) such as BUILDER, indicates a facility's mission criticality. Like other SMS indices, the MDI score is assigned using standardized procedures that produce objective, auditable, and credible ratings. A high MDI score indicates a missioncritical building that needs to be maintained at a high standard of functionality. A low MDI score indicates of negligible mission-criticality, and may suggest the potential for divesture or demolition. By linking each facility to 
the installation's mission, MDI scores communicate a critical detail not previously available to infrastructure decision makers.

This project produced three significant results. First, the general MDI process and interview questions were tailored to Army requirements by implementing the MDI at a large, complex test installation (White Sands Missile Range). Second, best practices for implementing the tailored MDI process at Army installations were documented for prospective use in future formal guidance. Third, the relation between the MDI process and other Army facility management systems was identified in order to facilitate the service-wide management of mission-critical facilities.

\subsection{Recommendations}

The authors recommend that data on facility interruptability and relocatability be collected as part of an annual ISR-I process. This approach would provide flexibility to provide up-to-date information as missions change, while making the data collection process less burdensome. In order to achieve consistent results, the ISR-I assessors providing the data must be properly trained. As implementation of this data collection begins, personnel with previous extensive training in the MDI interview process should facilitate the initial data gathering effort in order to assure the most accurate and consistent results.

It is also recommended that MDI assessments focus first on all Tier 1 mission elements, then all general support elements at each installation, since these two categories involve the highest degree of interdependence among missions. These include facilities supporting fire, water, electric, communications, transportation, DPW, and other basic support elements. Next, efforts should focus on facilities supporting the direct mission elements for each installation. Administrative facilities, housing facilities, and other general facilities should be defaulted to Army-wide MDI values as appropriate.

Finally, it is recommended that MDI information be stored in the BUILDER SMS to facilitate infrastructure SRM project prioritization. The MDI score, along with the component interruptability and relocatability ratings, should be stored for each facility. It is recommended MDI information also be added as data elements to the Army's real property database. 


\section{References}

Air Force Instruction 90-901, 1 April 2000, Operational Risk Management. http://www.epublishing.af.mil/shared/media/epubs/AFI90-901.pdf

Amekudzi, A., and S. McNeil. 2008. Infrastructure Reporting and Asset Management, Pages 141-146, Best Practices and Opportunities. Reston, VA: American Society of Civil Engineering.

Antelman, A., and C. Miller. 2002. Mission Dependency Index Validation Report. Special Publication SP-2113-SHR. Port Hueneme, CA: Naval Facilities Engineering Command, Naval Facilities Engineering Service Center.

http://www.fmlink.com/ProfResources/BestPractices/

http://www7.nationalacademies.org/FFC/Albert_Antelman_USNavy_Facility_Management_Triage_0ct_0 6_WP.pdf

http://www.appa.org/files/pressreleases/070906_execsummary_buildingsais.pdf

http://www.ifma.org/learning/events/fm3d08/files/best\%20practices/3.1\%20FM\%20Triage\%20\%20PRESENTATION\%200UTLINE.pdf

NAVFAC ESC. 2010. "MDI overview brief." PowerPoint presentation file linked at https://portal.navfac.navy.mil/portal/page/portal/navfac/navfac_ww_pp/navfac_nfesc_pp/m di/overview, accessed 3 September 2010.

OPNAVINST 3500.39b: http://www.safetycenter.navy.mil/instructions/orm/35000_39B.pdf 


\section{Acronyms and Abbreviations}

ACSIM - Assistant Chief of Staff for Installation Management

BCI - Building Condition Index

BFI - Building Functionality Index

BPI - Building Performance Index

CERL - Construction Engineering Research Laboratory

CI - Condition Index

DPW - Directorate of Public Works

ERDC - Engineer Research and Development Center

FCI - Facility Condition Index

FI - Functionality Index

GFEBS - General Fund Enterprise Business System

GIS - Geographic Information System

HQ - Headquarters

HQIIS - Headquarters Installation Information System

IFS - Integrated Facilities System

IMCOM - Installation Management Command

ISR-I - Installation Status Report- Infrastructure

IT - Information Technology

MDI - Mission Dependency Index

M\&R - Maintenance and Repair

O\&M - Operations and Maintenance 
OSD - Office Secretary of Defense

PP\&E - Property, Plant, and Equipment

PRV - Plant Replacement Value

RPUID - Real Property Unique ID

ROI - Return on Investment

SMS - Sustainment Management System

SRM - Sustainment, Restoration, Modernization 


\section{Appendix A: WSMR Functional Areas}

\begin{tabular}{|c|c|c|c|}
\hline Code & Functional Area & \#Facilities & Group \\
\hline TEDT-WS-CG & Office of the Commanding General & 2 & Command \\
\hline TEDT-WS-CS & Chief of Staff, Plans \& Operations & & Command \\
\hline TEDT-WS-JA & Staff Judge Advocate & & Command \\
\hline TEDT-WS-IG & Inspector General & & Command \\
\hline TEDT-WS-PA & Public Affairs & 2 & Command \\
\hline TEDT-WS-RM & Resource Management Directorate & 1 & Command \\
\hline TEDT-WS-TC & Commander, White Sands Test Center & & Command \\
\hline $\begin{array}{l}\text { TEDT-WS- } \\
\text { O,OS,SO,G }\end{array}$ & $\begin{array}{l}\text { Operations G3, Personnel, Logistics, Environmental, Security, } \\
\text { Safety, Site Defense }\end{array}$ & & Command \\
\hline IMWE-WSM-ZA & Office of the Garrison Commander & 2 & Command \\
\hline IMWE-WSM-HR & Human Resources & & \\
\hline IMWE-WSM-PAI & Plans, Analysis \& Integration & 1 & Command \\
\hline TEDT-WSD & Data Sciences Directorate & 74 & DSD \\
\hline TEDT-WSD-P & Data Processing Division & & DSD \\
\hline TEDT-WSD-P & Applied Software, Data Management, Real Time & & DSD \\
\hline TEDT-WSD-D & Distributed Systems Division & & DSD-Net \\
\hline TEDT-WSD-D & Inter-RangeControl Center & & DSD-Net \\
\hline TEDT-WSD-D & Network & & DSD-Net \\
\hline TEDT-WSD-D & LMR/Radio & & DSD-Net \\
\hline TEDT-WSD-I & Information Management Div & & DSD \\
\hline TEDT-WSD-I & Telephone & & DSD-Tele \\
\hline TEDT-WSD-I & Email & & DSD \\
\hline TEDT-WSD-I & Data/File/App/Financial/GIS/Collaboration/Web Servers & & DSD \\
\hline IMWE-WSM-SD & Law Enforcement \& Security Dir & & \\
\hline IMWE-WSM-SD & Law Enforcement Div & 42 & DES \\
\hline IMWE-WSM-SD & Security Counter Intelligence Div & 1 & DIS \\
\hline $\begin{array}{l}\text { IMWE-WSM-PW- } \\
\text { Fire }\end{array}$ & Fire \& Emergency Services Div & 27 & Fire \\
\hline
\end{tabular}




\begin{tabular}{|c|c|c|c|}
\hline Code & Functional Area & \#Facilities & Group \\
\hline IMWE-WSM-MW & Dir. Community Activities \& Housing & 63 & MWR \\
\hline IMWE-WSM-CH & Staff Chaplain & 3 & Chaplain \\
\hline TEDT-WSM & Materiel Test Directorate & 494 & MTD \\
\hline TEDT-WSM-T & Missiles \& Space Div & & MTD \\
\hline TEDT-WSM-F & Future Force Div & & MTD \\
\hline TEDT-WSM-O & Systems Performance \& Assessment Div & & MTD \\
\hline Pads & Pads & & MTD \\
\hline TEDT-WSS & System Engineering Directorate & 5 & SED \\
\hline TEDT-WSS-R & Range Integration Div & & SED \\
\hline TEDT-WSS-S & Sensor System Div & & SED \\
\hline TEDT-WSS-A & Software Systems \& Analysis Div & & SED \\
\hline TEDT-WSS-N & Network and Control Systems Div & & SED \\
\hline TEDT-WSV & Survivability, Vulnerability and Assessment Directorate & 44 & SVD \\
\hline TEDT-WSVA & Applied Environment Div & & SVD \\
\hline TEDT-WSVE & Electromagnetic Effects Div & & SVD \\
\hline TEDT-WSVM & Nuclear Effects Div & & SVD \\
\hline TEDT-WSR & Range Operations (RO) & 12 & ROD \\
\hline TEDT-WSR-D & $\begin{array}{l}\text { Data Collection Division (METOC, GPS, Optics, Radar, } \\
\text { Telemetry) }\end{array}$ & & ROD \\
\hline TEDT-WSR-C & $\begin{array}{l}\text { Operations Control Division (Flight Safety, Range Programs, } \\
\text { Range Control) }\end{array}$ & & ROD \\
\hline ROD & National Range & 126 & ROD \\
\hline ROD & Ammo, High Explosives Magazines & 4 & ROD-Expl \\
\hline ROD & Land (ranges) & 221 & ROD-Land \\
\hline \multirow[t]{6}{*}{ IMWE-WSM-LG } & Logistics & 93 & Logistics \\
\hline & $\begin{array}{l}\text { Plans \& Operations Division (Info Tech, manpower, safety, } \\
\text { security, budget) }\end{array}$ & & Logistics \\
\hline & Supply \& Services Division & & Logistics \\
\hline & HAZMAT & & HAZMAT \\
\hline & POL / FUELS & & POL/Fuels \\
\hline & $\begin{array}{l}\text { Transportation Division (traffic manager, freight, motor pool, } \\
\text { dispatch, vehicle operators) }\end{array}$ & & Transport \\
\hline
\end{tabular}




\begin{tabular}{|c|c|c|c|}
\hline Code & Functional Area & \#Facilities & Group \\
\hline & Transportation Maintenance Div & & Transport \\
\hline \multirow[t]{4}{*}{ IMWE-WSM-PW } & Public Works & 389 & DPW \\
\hline & Master Planning Div & & DPW \\
\hline & Business Operations \& Integration Div & & DPW \\
\hline & DPW Contractors & 8 & DPW Cont \\
\hline \multirow[t]{2}{*}{$\begin{array}{l}\text { IMWE-WSM-PW- } \\
\text { Env }\end{array}$} & Environment \& Safety Directorate & 140 & Env \\
\hline & Wildlife Area & & Wild \\
\hline \multirow[t]{2}{*}{$\begin{array}{l}\text { IMWE-WSM-PW- } \\
\text { Saf }\end{array}$} & Safety Division & & Safety \\
\hline & Explosive, Radiation, Protection Div & & Safety \\
\hline \multirow[t]{15}{*}{$\begin{array}{l}\text { IMWE-WSM-PW- } \\
\text { Ops }\end{array}$} & Operations \& Maintenance Div & & DPW-O\&M \\
\hline & Downrange Branch & & DownRang \\
\hline & Electrical Distribution & 35 & Elect-D \\
\hline & Water/Wastewater & 116 & Water-D \\
\hline & Natural Gas & 2 & NatGas-D \\
\hline & HVAC/Metal Section & 9 & HVAC-D \\
\hline & Building Repair Section & 3 & Repair-D \\
\hline & Roads \& Grounds Section & 12 & Roads-D \\
\hline & Refuse Collection/Garbage/Pest Ctrl & & Ref/Pest-D \\
\hline & Uprange Branch & 43 & UpRange \\
\hline & Electrical Distribution & & Elect-U \\
\hline & Water/Wastewater & & Water-U \\
\hline & Natural Gas & & NatGas-U \\
\hline & Roads \& Grounds Section & & Roads-U \\
\hline & Refuse Collection/Garbage/Pest Ctrl & & Ref/Pest-L \\
\hline Salinas & Uprange Branch - Salinas Peak & 19 & Various \\
\hline Stallion & Uprange Branch - Stallion & 47 & Various \\
\hline Rhodes Canyon & Uprange Branch - Rhodes Canyon & 26 & Various \\
\hline Oscura & Uprange Branch - Oscura & 25 & Various \\
\hline
\end{tabular}




\begin{tabular}{|c|c|c|c|}
\hline Code & Functional Area & \#Facilities & Group \\
\hline & Vacant & 150 & VacDem'd \\
\hline & Turn-in/Demo & 210 & VacDem'd \\
\hline & Orphans - Not Identified in RPI & 1159 & Orphans \\
\hline \multicolumn{4}{|c|}{ TENANTS } \\
\hline Medical & William Beaumont Medical Center & & MED \\
\hline Medical & McAfee U.S. Army Health Clinic & 2 & MED \\
\hline Medical & U.S. Army Dental Clinic & & MED \\
\hline Medical & Veterinary Clinic & 5 & VET \\
\hline TEDT-WST-O & Army Air Office & 21 & AAO \\
\hline DODAFC & DOD Area Frequency Coordinator & 1 & Command \\
\hline $\mathrm{CCM}$ & Center for Countermeasures (CCM) & 1 & $\mathrm{CCM}$ \\
\hline$\overline{A R L}$ & U.S. Army Research Laboratory-WSMR (AMSRD) & 52 & ARL \\
\hline TMDE3 (CAL Lab) & $\begin{array}{l}\text { USA Test Measurement \& Diagnostic Equip (TMDE Region 3) } \\
\text { - (Cal Lab) }\end{array}$ & 3 & CAL \\
\hline Navy & $\begin{array}{l}\text { Port Hueneme Div Naval Surface Warfare Center (PHD- } \\
\text { NSWC) }\end{array}$ & 33 & PHD-NSWC \\
\hline $\mathrm{AF}$ & Deputy for Air Force White Sands Missile Range & 5 & DAF \\
\hline AF - GEODDS & Grnd Based Electro-Optical Deep Space Surveillance & 4 & DAF \\
\hline AF - Lincoln Lab & Lincoln Lab (MIT) & 2 & DAF \\
\hline ACE & Army Corps of Engineers & 1 & COE \\
\hline USASDC & U.S. Army Strategic Defense Commn (USASDC) & & USASDC \\
\hline HELSTF & High Energy Laser System Test Facility & 72 & USASDC \\
\hline STRICOM & STRICOM (Redstone Arsenal) & 32 & STRICOM \\
\hline AAFES & Army Air Force Exchange Service (AAFES) & 5 & AAFES \\
\hline DECA & Defense Commissary Agency (DECA) & 1 & DECA \\
\hline NASA & NASA & 6 & NASA \\
\hline TRAC & TRAC (DARPA research unit?) & 4 & TRAC \\
\hline
\end{tabular}




\begin{tabular}{|l|l|l|l|}
\hline Code & Functional Area & \#Facilities & Group \\
\hline & & & \\
\hline National Guard & National Guard & 1 & NTG \\
\hline & & & \\
\hline ATRC & U.S. Army TRADOC Analysis Center-WSMR (ATRC) & 0 & ATRC \\
\hline & & & \\
\hline IMSW-WSM-PW-M & General Services Admin, Region 7 (GSA) & 0 & GSA \\
\hline & & & \\
\hline SFCA-SR-WS & U.S. Army Contracting Agency & 0 & USA_Cntr \\
\hline & & & \\
\hline
\end{tabular}




\section{Appendix B: Unit Interview Sheet}

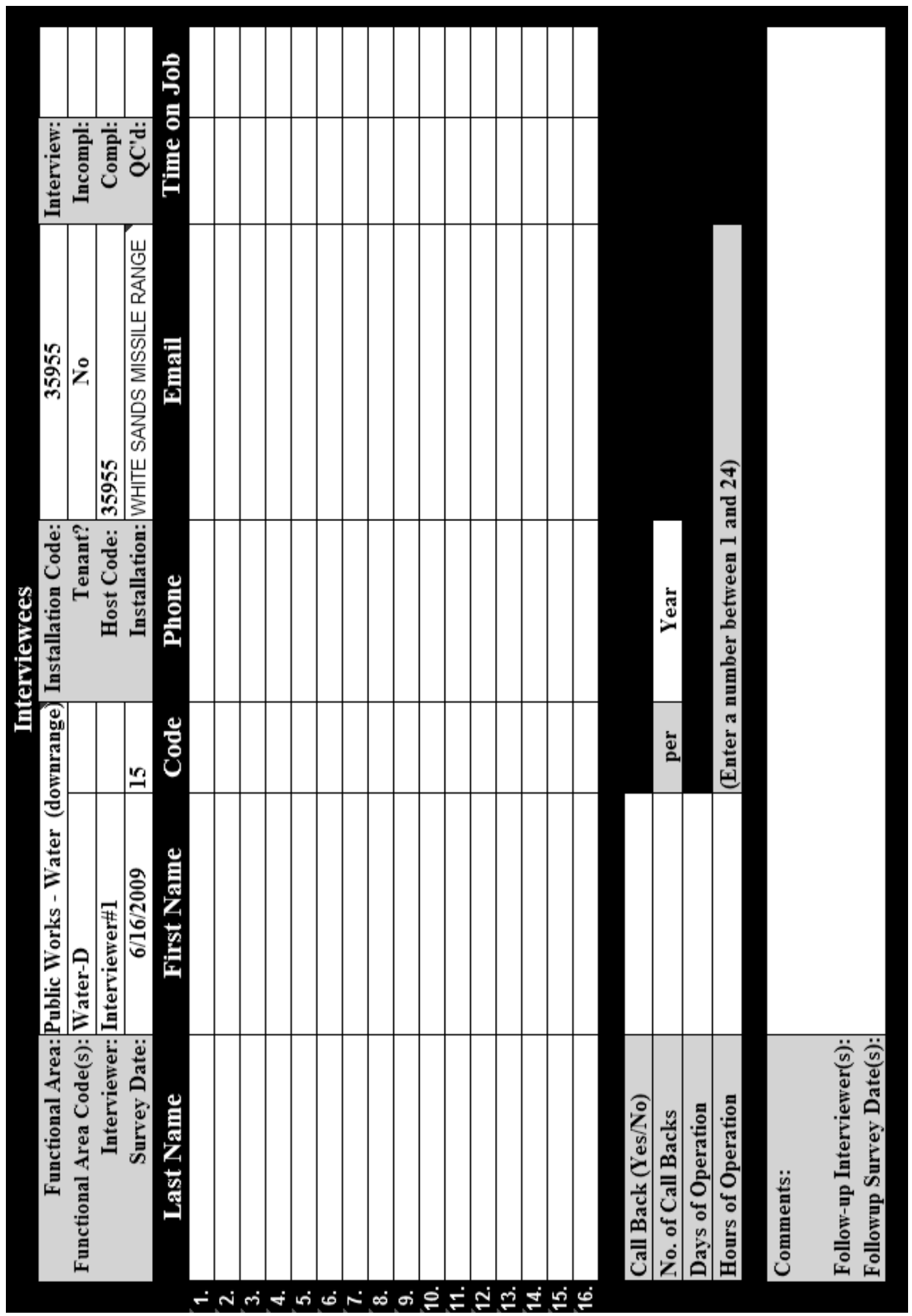




\section{Appendix C: Intradependency Questions}

Question \#1: If there is scheduled maintenance or an upgrade to your facility, how long could your facility be down without adverse impact to your mission?

I - Immediate (must be maintained continuously (24/ 7))

U - Urgent (minutes, not to exceed $1 \mathrm{hr}$ )

B - Brief (hours, not to exceed 24 hours)

S - Short (days, not to exceed 7 days)

P - Prolonged (weeks, not to exceed 1 month)

E - Extended (1 month - 6 months, requires up to 1 week to make operational)

F - Future (6 months - 2 years, requires up to 2 months to make operational)

M- Mothballed (2+years, requires several months to make operational).

A - Abandoned (secure facility and walk away)

D - Demolished (turn-in or demolished, available for use by others)

Question \#2: If your facility were not functional, could you continue performing your mission by using another facility, or by setting up temporary facilities? (i.e., What is the level of "pain"?)

I - Impossible (an alternate location is not available, requires an emergency appropriation from Congress)

X - Extremely Difficult (an alternate location exists with minimally acceptable capabilities, but relocation would require a huge in-house effort (money/ man-hours), dislocation of another major occupant, and/ or a huge contracting effort for additional services and no available contract mechanism is in place to replace the services being provided. Mission readiness would be greatly compromised.)

V - Very Difficult (an alternate location exists with marginally acceptable capabilities, but relocation would require a significant in-house effort (money/man-hours), dislocation of another major occupant, and/ or a significant contracting effort for additional services and no available contract mechanism is in place to replace the services being provided. Mission readiness would be minimally compromised.) 
D - Difficult (an alternate location exists with acceptable capabilities and capacity but relocation would require a measurable and unbudgeted level of effort (money/man-hours), and mission readiness capabilities would not be compromised in the process.)

$\mathbf{P}$ - Possible (an alternate location is readily available with sufficient capabilities and capacity, in addition the level of effort has been budgeted for or can be easily absorbed) 


\section{Appendix D: Interdependency Questions}

Question \#3: For each Functional Area that provides you services, how long could the services be interrupted before your mission readiness was negatively impacted, or else howlong can you wait until they resolve your request?

$\mathbf{N}$ - None (any interruption will instantly impact mission readiness)

U - Urgent (minutes, not to exceed 1 hour)

B - Brief (hours, not to exceed 24 hours and there are insufficient redundancies built into the system to absorb a brief interruption)

S - Short (days, not to exceed 7 days, and there are sufficient and effective redundancies built into the system to cover brief interruptions)

P - Prolonged (weeks, not to exceed 1 month)

E - Extended (months, not to exceed 6 months)

F - Future (6 months - 2 years)

Question \#4: If the Functional Area was not available, how difficult is it to replace or replicate the service? (What is the level of "pain"?)

I - Impossible (there are no known redundancies or excess/ surge capacities available, or there are no viable commercial alternatives - only this site/ command can provide these services)

X - Extremely Difficult (there are minimally acceptable redundancies or excess/ surge capacities available, or there are limited commercial alternatives, and there are no readily available contract mechanisms in place to replace the services. Mission readiness is greatly compromised)

V - Very Difficult (there are marginally acceptable redundancies or excess/ surge capacities available, or there are viable commercial alternatives, and there are contract mechanisms in place or can readily be put in place to replace the services. Mission readiness is minimally compromised.)

D - Difficult (services exist and are available, but the form of delivery is ill defined or will require a measurable and unbudgeted level of effort to obtain (money/man-hours). There is a contract mechanism in place to replace the services. Mission readiness capabilities would not be compromised in the process.)

P - Possible (services exist, are available, and are well defined) 


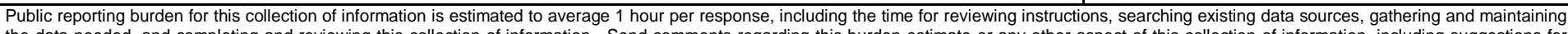

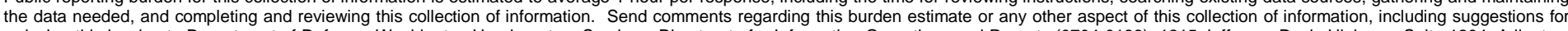

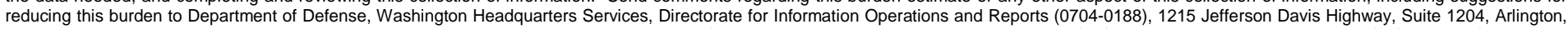

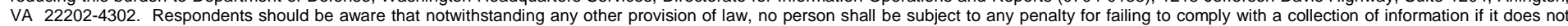
display a currently valid OMB control number. PLEASE DO NOT RETURN YOUR FORM TO THE ABOVE ADDRESS.
1. REPORT DATE (DD-MM-YYYY)
2. REPORT TYPE
3. DATES COVERED (From - To)

September 2010 Final

\section{TITLE AND SUBTITLE}

Development of the Army Facility Mission Dependency Index for Infrastructure Asset

Management

5a. CONTRACT NUMBER

5b. GRANT NUMBER

5c. PROGRAM ELEMENT NUMBER

ITTP

\section{AUTHOR(S)}

Michael N. Grussing, Steve Gunderson, Mary Canfield, Ed Falconer, Albert Antelman, and Samuel L. Hunter

5d. PROJECT NUMBER

FY09-39

5e. TASK NUMBER

5f. WORK UNIT NUMBER

\section{PERFORMING ORGANIZATION NAME(S) AND ADDRESS(ES)}

U.S. Army Engineer Research and Development Center

Construction Engineering Research Laboratory

8. PERFORMING ORGANIZATION REPORT NUMBER

ERDC/CERL TR-10-18

P.O. Box 9005

Champaign, IL 61826-9005

\section{SPONSORING I MONITORING AGENCY NAME(S) AND ADDRESS(ES)}

Office of the Assistant Chief of Staff for Installation Management

Facilities Branch (DAIM-ODF)

2511 Jefferson Davis Highway

Arlington, VA 22202

10. SPONSOR/MONITOR'S ACRONYM(S)

ACSIM

11. SPONSOR/MONITOR'S REPORT NUMBER(S)

\section{DISTRIBUTION I AVAILABILITY STATEMENT}

Approved for public release; distribution is unlimited.

\section{SUPPLEMENTARY NOTES}

\section{ABSTRACT}

This report describes a Mission Dependency Index (MDI) developed for U.S. Army facility asset management. The MDI is an indicator of mission-related importance of Army infrastructure elements to be used for the purpose of providing more effective local prioritization of facilities for sustainment, restoration, and modernization (SRM) actions. It does this by evaluating the mission impact of interrupting a function or relocating where it is provided. The index is reported on a scale of 0-100, and is analogous in that respect with existing Corps of Engineers Sustainment Management System (SMS) indices. As part of this work, an MDI methodology directly fit to Army-specific missions, facility resource capabilities, and organizational structure was developed. This was accomplished through a pilot implementation at White Sands Missile Range. The objectives of the demonstration were to identify Army-specific MDI criteria, develop a standardized implementation process, determine the steps for integrating MDI information into garrison-level and Army-level facility management business processes, and identify considerations and requirements for incorporating Army MDI criteria into the BUILDER ${ }^{\circledR}$ SMS. The results of an MDI analysis, as facilitated using the implementation and integration procedures recommended here, will enable facility decision makers to focus on infrastructure most critical to mission effectiveness.

\section{SUBJECT TERMS}

asset management, Mission Dependency Index (MDI), Sustainment Management Systems (SMS), infrastructure, evaluation, Installation Status Report for Infrastructure (ISR-I), mission criticality

\section{SECURITY CLASSIFICATION OF:}

\section{a. REPORT}

Unclassified

b. ABSTRACT
Unclassified

17. LIMITATION
OF ABSTRACT

\begin{tabular}{l|l} 
18. NUMBER \\
OF PAGES
\end{tabular}

51 19a. NAME OF RESPONSIBLE PERSON

19b. TELEPHONE NUMBER (include
area code) 